\title{
Chirality Transfer in Gold Nanoparticles by L-Cysteine Amino Acid: A First-Principles Study
}

\author{
Jordi Morales-Vidal, Núria López, ${ }^{\circledR}$ and Manuel A. Ortuño*(๑) \\ Institute of Chemical Research of Catalonia (ICIQ), the Barcelona Institute of Science and Technology (BIST), Av. Països Catalans \\ 16, 43007 Tarragona, Spain
}

Supporting Information

\begin{abstract}
The use of chiral organic ligands during nanoparticle synthesis is key to designing optically active materials for biological and catalytic applications. To understand such complex processes at the atomic level, we performed DFT simulations and built Wulff thermodynamic structures to model the impact of amino acids on gold nanoparticle morphology. Herein, we report the adsorption of L-cysteine at low and high coverage on achiral gold surfaces (111), (110), and (100) as well as chiral gold terminations (321) and (32) $)$. We found that L-cysteine preferentially binds to $\mathrm{Au}(321)$, inducing a chiral templating effect, and the enantiomeric enrichment is favored at low coverage situations.
\end{abstract}

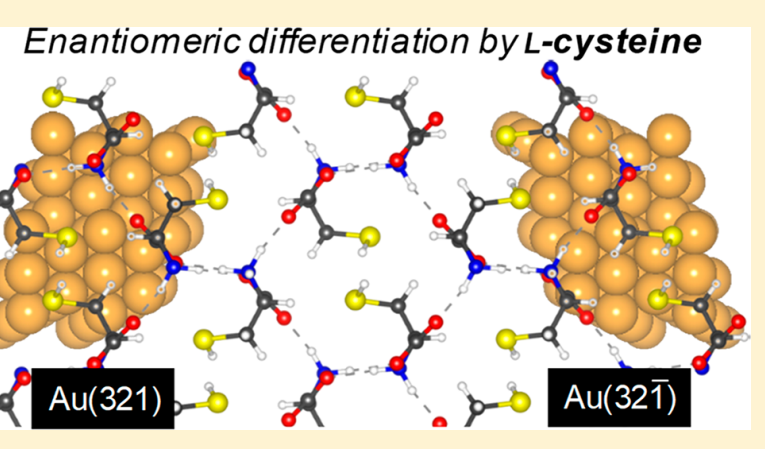

\section{INTRODUCTION}

The precise control of morphologies and surface terminations of metal nanoparticles (NPs) is a major focus in synthetic nanotechnology, as their shape is intimately related to their activity and properties. ${ }^{1-3}$ In the past decades, the shape control of gold nanoparticles (AuNPs) ( $^{4-6}$ has made great advances due to the relevance of these systems in sensing, biomedicine, ${ }^{8,9}$ and catalysis. ${ }^{10,11}$

The role that NPs play in many biological ${ }^{12}$ and optical ${ }^{13}$ applications creates the need to develop chiral materials. ${ }^{14,15}$ The chiral templating of nanocrystals ${ }^{16}$ can be approached by using surface modifiers during nanoparticle growth. ${ }^{17}$ Since the pioneering synthesis of optically active $\mathrm{Au}_{28}$ clusters, ${ }^{18}$ the preparation of chiral AuNPs has quickly developed. ${ }^{19}$ Quite recently, Lee et al. reported the synthesis of twist-shaped chiral AuNPs using amino acids and peptides. ${ }^{20}$ Moreover, the impact of chirality of AuNP has been recently studied for optical $^{21}$ and catalytic ${ }^{22}$ applications.

To predict nanocrystal shapes, ${ }^{23}$ we need a proper description of the interaction between metal surfaces and organic ligands. ${ }^{24,25}$ In that sense, computational modeling comes into play to provide atomistic detail at the nanoscale. ${ }^{26-28}$ Adsorption studies on gold have been reported for a myriad of surface modifiers, such as thiol derivatives ${ }^{29}$ as well as amino acids and peptides, ${ }^{30-33}$ among other ligands. ${ }^{34-37}$ Because of the particular properties of the $\mathrm{Au}-\mathrm{S}$ interface, ${ }^{38}$ the interaction between the sulfur-containing L-cysteine amino acid and Au surfaces is currently exploited to transfer chirality to AuNPs. ${ }^{20-22}$ Most theoretical studies focus on low-Millerindex facets, ${ }^{39-45}$ some of them including dynamics, ${ }^{46,47}$ but only a few reports deal with chiral surfaces, ${ }^{48}$ such as $\mathrm{Au}(321)^{49}$ and $\mathrm{Au}\left(\begin{array}{lll}17 & 11 & 9\end{array}\right) .^{50,51}$ With regard to the morphology, the Wulff theorem ${ }^{52}$ provides a robust approach to predict the thermodynamic equilibrium shape of NPs. The method relies on the energy required to create each surface, $\gamma_{\mathrm{s}}$. In the presence of solvent or ligand modifiers, the surface energies $\gamma_{\mathrm{s}}$ are replaced with those of the interface, $\gamma_{\mathrm{s}}{ }^{\prime}$. This protocol $^{53}$ has been successfully employed to describe the equilibrium shape of thiolate-decorated $\mathrm{AuNPs}^{54}$ as well as the effect of $\mathrm{CO}$ adsorption on different AuNP morphologies. ${ }^{55}$

Nevertheless, the impact of enantiomeric differentiation by chiral modifiers on nanostructures has not been addressed. Here, we present density functional theory (DFT) simulations to study the chirality induced to AuNPs by organic ligands (Figure 1). We report the adsorption of the natural L-cysteine enantiomer on achiral gold surfaces (111), (110), and (100) as well as the enantiomeric gold facets (321) and (32 $\overline{1})$. We consider both low and high coverage situations and evaluate

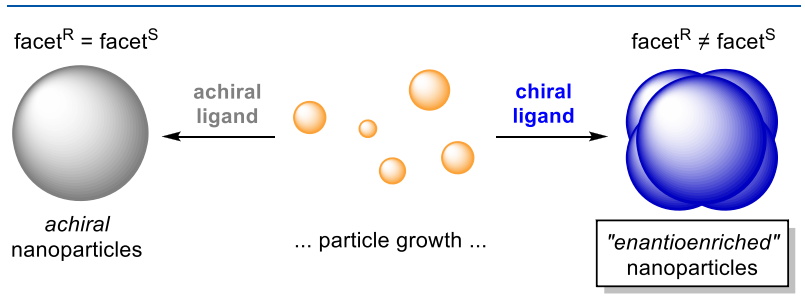

Figure 1. Differentiation of enantiomeric metal facets by chiral modifiers. 
the impact of the chiral ligand on AuNP morphologies via Wulff constructions.

\section{COMPUTATIONAL METHODS}

All calculations were performed at the density functional theory (DFT) level using the Vienna Ab initio Simulation Package (VASP). ${ }^{56,57}$ The PBE exchange-correlation functional $^{58}$ was used together with van der Waals corrections ${ }^{59}$ via the Grimme D3 approach. ${ }^{60}$ We employed the projected augmented wave (PAW) method ${ }^{61}$ to describe the core electrons and plane waves with a kinetic cutoff of $450 \mathrm{eV}$ to describe valence electrons.

Periodic boundary conditions were employed to model $\mathrm{Au}$ surfaces for three low-Miller-index planes, (111), (110), and (100), and two high-Miller-index planes, (321) and (32 $\overline{1})$. The (111) and (110) facets were modeled with 4 atomic layers, the (100) facet was constructed with 8 atomic layers, and the (321) and $(32 \overline{1})$ terminations were built with 16 atomic layers. The number of layers used to construct each surface was determined by their openness degree. ${ }^{62}$ In all cases, the half bottom layers were kept fixed to mimic the bulk while the half upper layers were fully relaxed. A 15 Å vacuum region between slabs and a dipole correction along the $z$-axis were employed. ${ }^{63}$

The studied $\mathrm{Au}$ facets were described with different models: $\mathrm{Au}(111)$ and $\mathrm{Au}(100)$ were represented by $\mathrm{p}(4 \times 4)$ slabs, $\mathrm{Au}(110)$ was modeled by a $\mathrm{p}(3 \times 3)$ slab, and $\mathrm{Au}(321)$ and $\mathrm{Au}(32 \overline{1})$ were described by $\mathrm{p}(2 \times 2)$ slabs. The Brillouin zone for all models was sampled by a $3 \times 3 \times 1 k$-point mesh generated through the Monkhorst-Pack method. ${ }^{64}$ The crystal morphology model for the Wulff construction ${ }^{52}$ was created using VESTA (Visualization for Electronic and STructural Analysis) version 4.5.0. ${ }^{65}$ The shapes were described as a function of surface energies and the symmetry point group of the nanoparticle. Because the presence of the chiral ligand distorts the otherwise equivalence of $\mathrm{Au}(321)$ and $\mathrm{Au}(32 \overline{1})$ enantiomeric facets, we performed a descent in symmetry from $\mathrm{F}_{m-3 m}$ to $\mathrm{F}_{432}{ }^{20}$ to remove all mirror planes when computing equilibrium shapes.

All inputs and final structures can be found in ioChem$\mathrm{BD},{ }^{66,67}$ an open access repository for computational data. ${ }^{68}$

\section{RESULTS AND DISCUSSION}

In the present work, we explore the configurational space of $\mathrm{L}^{-}$ cysteine adsorbed on different gold surfaces, compute the adsorption energies at low and high coverages, and derive the thermodynamic equilibrium shapes of AuNPs.

The different gold terminations considered in this study are shown in Figure $2 \mathrm{a} . \mathrm{Au}(111), \mathrm{Au}(100)$, and $\mathrm{Au}(110)$ are achiral low-Miller-index surfaces, while $\mathrm{Au}(321)$ and $\mathrm{Au}(32 \overline{1})$ correspond to high-Miller-index $(h \neq k \neq l$ and $h \cdot k \cdot l \neq 0)$ surfaces that exhibit chiral kinks. Based on the Cahn-IngoldPrelog rules for organic molecules, the surface nomenclature for $\mathrm{Au}(321)$ and $\mathrm{Au}(32 \overline{1})$ would be $R$ and $S$, respectively. ${ }^{69}$ The computed surface energies $\gamma_{\mathrm{s}}$ for the achiral $\mathrm{Au}(111)$, $\mathrm{Au}(100)$, and $\mathrm{Au}(110)$ facets are $1.42,1.54$, and $1.59 \mathrm{~J} \mathrm{~m}^{-2}$, respectively. Such a trend is in line with the literature, ${ }^{70,71}$ although the values slightly differ when using Grimme D2 $2^{72}$ with modified parameters for the metal ${ }^{73}$ to describe van der Waals interactions (Table S1). The $\gamma_{\mathrm{s}}$ value for both enantiomeric facets $\mathrm{Au}(321)$ and $\mathrm{Au}\left(32 \frac{1}{1}\right)$ is $1.59 \mathrm{~J} \mathrm{~m}^{-2}$, similar to that for $\mathrm{Au}(110)$. (a)
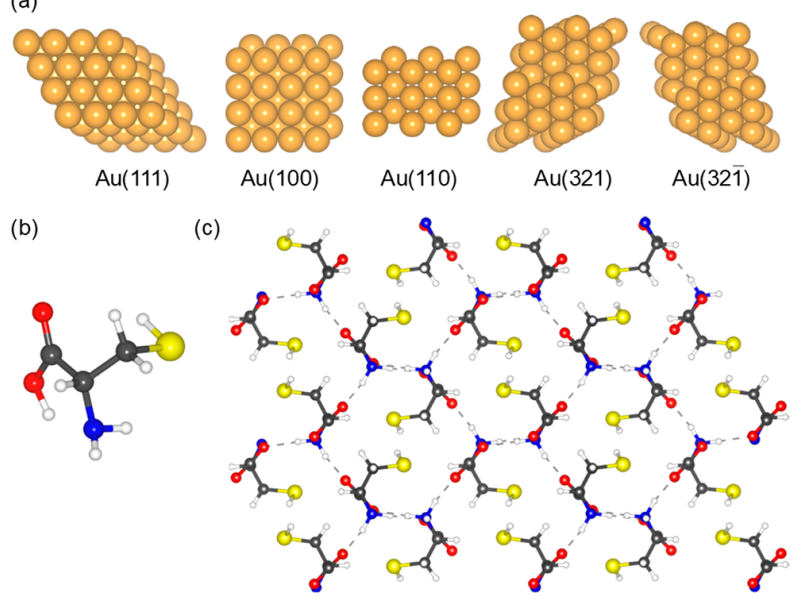

Figure 2. (a) Au facets considered in this study. (b) Optimized gasphase structure of L-cysteine. (c) Optimized crystal lattice of Lcysteine. Legend: $\mathrm{Au}=$ orange, $\mathrm{S}=$ yellow, $\mathrm{O}=$ red, $\mathrm{N}=$ blue, $\mathrm{C}=$ gray, and $\mathrm{H}=$ white.

As for the ligand, L-cysteine is usually found in zwitterionic form in both the solution and solid state. However, in the gas phase only the neutral structure exists. ${ }^{74}$ Indeed, all attempts to optimize zwitterionic species in the gas phase led to neutral compounds (Figure $2 \mathrm{~b}$ ). To properly describe its zwitterionic nature, we optimized the unit cell of a crystal structure of Lcysteine (Figure 2c), ${ }^{75}$ which contains four molecules in zwitterionic form connected through a $\mathrm{H}$-bonding interaction network between $\left[\mathrm{NH}_{3}\right]^{+}$and $[\mathrm{COO}]^{-}$fragments (optimized $\mathrm{NH}$... O distances in the range 1.7-1.9 $\AA$ ). As reference to compute subsequent adsorption energies, we use the solidstate energy. ${ }^{76}$

The adsorption energies $E_{\text {ads }}$ of L-cysteine on the different $\mathrm{Au}$ surfaces were computed using the following expression:

$$
E_{\text {ads }}=E_{S-\mathrm{L}}-E_{\mathrm{S}}-n E_{\mathrm{L}}
$$

where $E_{\mathrm{S}-\mathrm{L}}$ is the energy of $\mathrm{L}$-cysteine on the metal surface, $E_{\mathrm{S}}$ is the energy of the metal surface, $E_{\mathrm{L}}$ is the energy of one $\mathrm{L}$ cysteine ligand from the optimized crystal structure, and $n$ is the number of molecules adsorbed.

Adsorption Energies at Low Coverage. In this section, we report the adsorption energies of only one L-cysteine molecule on different $\mathrm{Au}$ surfaces to model a low concentration of organic modifier. We ensured that our slab models reproduce a low coverage scenario since the periodic images of L-cysteine were separated by at least $4.7 \AA$.

First, we fully explored the configurational space of one Lcysteine molecule on $\mathrm{Au}(111)$ and $\mathrm{Au}(321)$ surfaces by considering up to six different configurations as shown in Figure 3. A1 describes the zwitterionic form found in the crystal structure (Figure 2c) with a $\mathrm{SH}$ group bound to the surface. However, in the absence of $\mathrm{H}$-bond interactions between neighboring molecules, such a configuration is not stable and evolved toward neutral species on both surfaces. A2 also corresponds to a zwitterionic form where the negative charge is placed on the sulfur atom bound to the surface. B stands for a neutral species with a SH group. $\mathbf{C 1}$ and $\mathbf{C 2}$ stand for zwitterionic and neutral states with a deprotonated sulfur atom, where the $\mathrm{H}$ is included as $1 / 2$ of $\mathrm{H}_{2}{ }^{49}$ Similar to $\mathrm{A}$, only the neutral form C2 is stable. Finally, D describes the dissociation of the $\mathrm{S}-\mathrm{H}$ bond on the surface. 

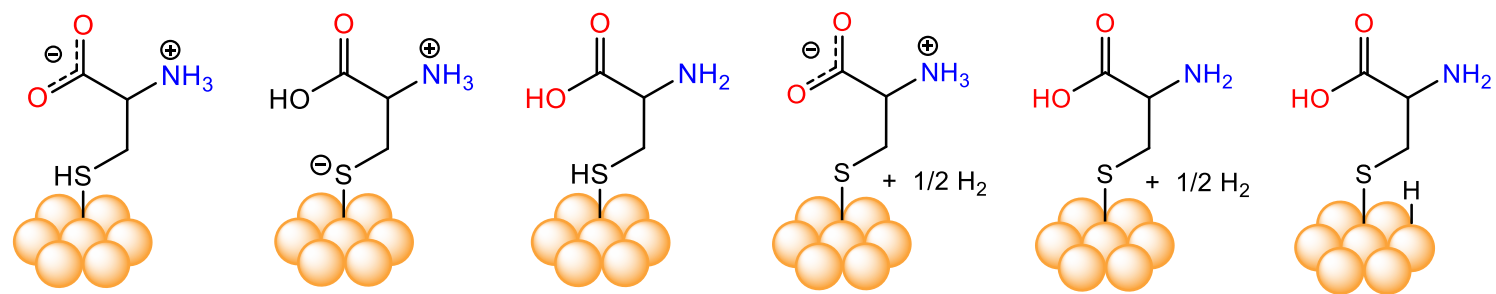

\begin{tabular}{l|c}
$E_{\text {ads }} / \mathbf{e V}$ & $\mathbf{A 1}$ \\
$\mathrm{Au}(111)$ & not stable \\
$\mathrm{Au}(321)$ & not stable
\end{tabular}

A2
0.58
-0.58

B
0.65
0.19

C1

not stable

not stable
C2

0.83

0.08
D

1.00

0.22

Figure 3. Configurational space of L-cysteine adsorbed on selected facets, $\mathrm{Au}(111)$ and $\mathrm{Au}(321)$.

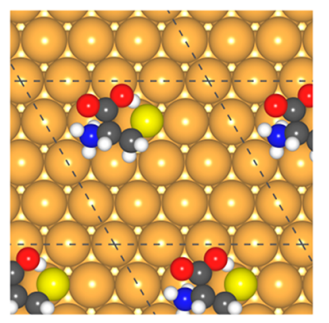

Surface $A u(111)$

$E_{\text {ads }} / \mathrm{eV} \quad 0.58$

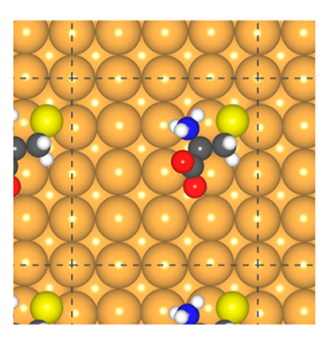

$\mathrm{Au}(100)$

$-0.03$

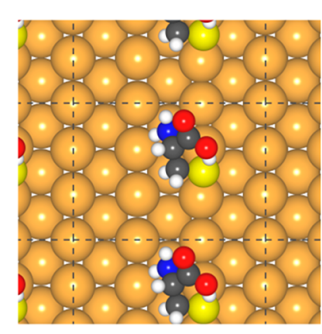

$\mathrm{Au}(110)$

$-0.26$

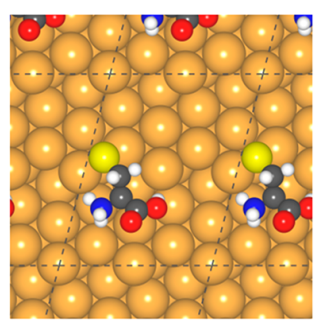

$\mathrm{Au}(321)$

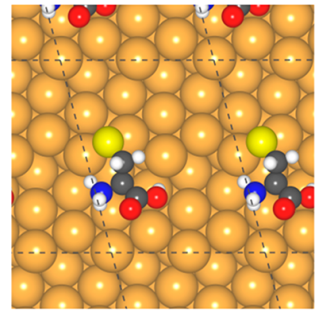

$\mathrm{Au}(32 \overline{1})$

$-0.48$

Figure 4. Most stable low-coverage structures and $E_{\text {ads }}(\mathrm{eV})$ for Au surfaces. Legend: $\mathrm{Au}=$ orange, $\mathrm{S}=$ yellow, $\mathrm{O}=$ red, $\mathrm{N}=$ blue, $\mathrm{C}=\mathrm{gray}$, and $\mathrm{H}=$ white.

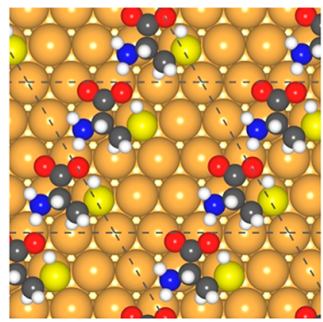

Surface

$E_{\text {ads }} / \mathrm{eV}$

$\mathrm{Au}(111)$

0.28

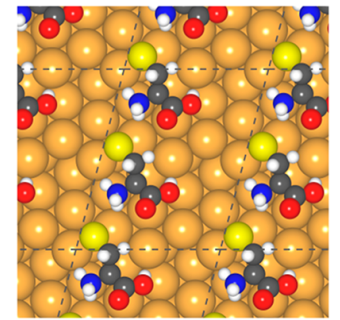

\section{Surface}

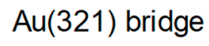

$E_{\text {ads }} / \mathrm{eV}$

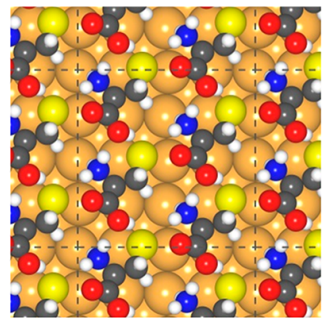

$\mathrm{Au}(100)$

$-0.73$

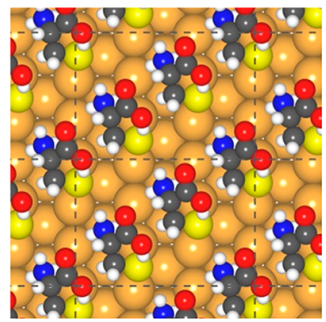

$\mathrm{Au}(110)$

$-1.33$

Figure 5. Most stable high-coverage structures and $E_{\text {ads }}(\mathrm{eV})$ for Au surfaces. Legend: $\mathrm{Au}=$ orange, $\mathrm{S}=$ yellow, $\mathrm{O}=$ red, $\mathrm{N}=$ blue, $\mathrm{C}=$ gray, and $\mathrm{H}$ = white.

The adsorption energies of the most stable conformers for the previously described configurations are collected in Figure 3 , where the zero of energies corresponds to the clean surface plus one L-cysteine molecule. For $\mathrm{Au}(111)$, the most stable configuration is $\mathrm{A} 2$ with an $E_{\text {ads }}$ of $0.58 \mathrm{eV}$. The presence of the
$[\mathrm{S}]^{-}$moiety in $\mathbf{A} 2$ agrees with the well-known affinity between thiolate groups and gold. ${ }^{29}$ It is worth noting that all adsorption processes on $\mathrm{Au}(111)$ are endothermic due to the stability of (i) the crystal structure taken as reference and (ii) the low-Miller-index surface. When considering an isolated 
L-cysteine molecule in the gas phase as reference (prime notation), all adsorption energies $E_{\text {ads }}$ ' become exothermic, being $\mathbf{A} 2$ again the most stable configuration with an $E_{\mathrm{ads}}{ }^{\prime}$ of $-1.02 \mathrm{eV}$ (Table S2). The $\mathrm{Au}(321)$ surface follows the same trend, where $\mathbf{A 2}$ is again the most stable structure. However, because of the lower stability of $\mathrm{Au}(321)$ compared to $\mathrm{Au}(111)$, the $E_{\text {ads }}$ is now exothermic with a value of $-0.58 \mathrm{eV}$. When the gas-phase reference is used, the $E_{\mathrm{ads}}{ }^{\prime}$ increases up to $-2.19 \mathrm{eV}$ (Table S2).

Figure 4 shows the optimized structures and $E_{\text {ads }}$ for all low coverage situations in the studied Au facets (a thorough study of structures on chiral surfaces can be found in Table S3). The most favorable adsorption site is top for $\mathrm{Au}(111)$, bridge for $\mathrm{Au}(100)$ and $\mathrm{Au}(110)$, and bridge of a step for $\mathrm{Au}(321)$ and $\mathrm{Au}(32 \overline{1})$. Adsorption processes are endothermic for $\mathrm{Au}(111)$ with $E_{\text {ads }}$ of $0.58 \mathrm{eV}$, isoenergetic for $\mathrm{Au}(100)$, and exothermic for $\mathrm{Au}(110), \mathrm{Au}(321)$, and $\mathrm{Au}(32 \overline{1})$ with $E_{\mathrm{ads}}$ of $-0.26,-0.58$, and $-0.48 \mathrm{eV}$, respectively. With regard to chiral surfaces, the $[\mathrm{S}]^{-}$group binds at the same bridge site of the step for both facets, while the relative position of the amino $\left[\mathrm{NH}_{3}\right]^{+}$and the carboxylic acid $[\mathrm{COOH}]$ moieties with respect to the terrace is different. These structures represent 3-point contact models for chiral recognition. ${ }^{48}$ As a result, the adsorption of $\mathrm{L}$-cysteine is preferred on $\mathrm{Au}(321)$ compared to $\mathrm{Au}(32 \overline{1})$ by $0.10 \mathrm{eV}$, in line with recent experiments. ${ }^{20}$ Such an energy difference would break the symmetry between terminations and induce an enantio-enriched growth of AuNPs.

Adsorption Energies at High Coverage. We next consider the adsorption of several L-cysteine molecules on $\mathrm{Au}$ facets to mimic a high coverage situation. Following the results from Figure 3, we only evaluated the configurations A1, A2, and $\mathbf{B}$.

To estimate the number of molecules required to mimic a high coverage for all considered models, we extensively explore conformations with up to four L-cysteine molecules on each $\mathrm{Au}$ surface. Using adsorption energies per molecule as criterion (Table S5), we report $\mathrm{Au}(111), \mathrm{Au}(321)$, and $\mathrm{Au}(32 \overline{1})$ with two molecules, $\mathrm{Au}(110)$ with three molecules, and $\mathrm{Au}(100)$ with four molecules. ${ }^{77}$

The most stable structures for each surface are shown in Figure 5 (a thorough study of structures on chiral surfaces can be found in Table S4). For $\mathrm{Au}(111)$, the configuration $\mathbf{A 1}$ is the most favored with an overall $E_{\text {ads }}$ of $0.28 \mathrm{eV}$. We observe intermolecular $\mathrm{H}$-bond interactions between $\left[\mathrm{NH}_{3}\right]^{+}$and $[\mathrm{COO}]^{-}$moieties with $\mathrm{H} \cdots \mathrm{O}$ distances of ca. $1.6 \AA$, which are comparable to the patterns found in the crystal (Figure 2c). This structure also exhibits intramolecular contacts between adsorbed $[\mathrm{SH}]$ and $[\mathrm{COO}]^{-}$that were absent in the crystal. For $\mathrm{Au}(100)$ and $\mathrm{Au}(110)$, the thiolate configurations $\mathbf{A 2}$ are the most stable, with exothermic $E_{\text {ads }}$ values of -0.73 and $-1.33 \mathrm{eV}$, respectively. The $\mathrm{Au}(100)$ structure features intermolecular H-bond interactions between $\left[\mathrm{NH}_{3}\right]^{+}$and $[\mathrm{COOH}]$. With regard to the facet $\mathrm{Au}(321)$, two L-cysteine molecules preferentially bind at bridge positions with an $E_{\mathrm{ads}}$ of $-1.21 \mathrm{eV}$, in line with the results at low coverage, while the top configuration has an $E_{\text {ads }}$ of $-0.97 \mathrm{eV}$. However, for the facet $\mathrm{Au}(32 \overline{1})$, the structure at bridge sites $(-0.88 \mathrm{eV})$ creates close contacts between neighboring molecules (distances $\mathrm{O} \cdots[\mathrm{S}]^{-}$of ca. $3.3 \AA$ ). In such a situation, the $[S]^{-}$groups move to top positions to yield a more favorable $E_{\text {ads }}$ of $-1.14 \mathrm{eV}$. The energetic preference of $0.07 \mathrm{eV}$ toward $\mathrm{Au}(321)$ is similar to that of $0.10 \mathrm{eV}$ found for the low-coverage scenario.
With regard to solvation, this study does not consider explicit water molecules, which would require the use of molecular dynamics simulations with reactive ${ }^{78}$ and polarizable $^{79}$ force fields. Although water molecules will unlikely compete with L-cysteine for surface sites on $\mathrm{Au}$, they can indeed act as proton shuttles during adsorption mechanisms. ${ }^{47}$ Nevertheless, because of the strong interaction between $\mathrm{Au}$ and $S$ in gold-cysteine interfaces, a gas-phase approach already provides useful trends as far as chiral discrimination concerns.

Equilibrium Shape of Au Nanoparticles. With $\gamma_{s}$ of clean $\mathrm{Au}$ facets and $E_{\text {ads }}$ of L-cysteine at hand, we computed the adsorption-corrected $\gamma_{s}{ }^{\prime}$, which describes the interface tension between $\mathrm{Au}$ and the amino acid for low and high coverage according to the following equation:

$$
\gamma_{\mathrm{s}}^{\prime}=\gamma_{\mathrm{s}}+E_{\mathrm{ads}} / A
$$

The results are collected in Table 1 . As expected for the clean system, the most stable surface termination is $\mathrm{Au}(111)$. At low

Table 1. Clean $\gamma$ and Corrected $\gamma^{\prime}$ Surface Energies $\left(\mathrm{J} \mathrm{m}^{-2}\right)$ for Au Facets

\begin{tabular}{cccccc} 
& \multicolumn{5}{c}{$\gamma_{\mathrm{s}}{ }^{\prime}\left(\mathrm{J} \mathrm{m}^{-2}\right)$} \\
\cline { 2 - 6 } & $(111)$ & $(100)$ & $(110)$ & $(321)$ & $(32 \overline{1})$ \\
clean $^{a}$ & 1.42 & 1.54 & 1.59 & 1.59 & 1.59 \\
low coverage & 1.50 & 1.54 & 1.56 & 1.52 & 1.53 \\
high coverage & 1.46 & 1.46 & 1.39 & 1.44 & 1.45 \\
${ }^{a}$ The experimental surface energy for Au is $1.54 \mathrm{~J} \mathrm{~m}^{-2} .{ }^{.0}$ \\
\hline
\end{tabular}

coverage the $\gamma_{s}^{\prime}$ values are rather close for all facets, while at high coverage such a trend changes, and $\mathrm{Au}(110)$ appears as the most stable surface.

Thermodynamic models based on Wulff constructions are then computed using $\gamma_{\mathrm{s}}$ for clean surfaces and $\gamma_{\mathrm{s}}{ }^{\prime}$ for low- and high-coverage terminations. With regard to the symmetry of the NP, all facets in the $\mathrm{F}_{m-3 m}$ point group are chemically equivalent. However, to account for the chirality introduced by $\mathrm{L}$-cysteine, we descent to the $\mathrm{F}_{432}$ point group to remove all mirror planes and break the symmetry between enantiomeric surfaces.

The resulting equilibrium shapes and the contributions of each surface as percentage are shown in Figure 6. For the clean system, the dominant surface is $\mathrm{Au}(111)$ with $47 \%$ followed by $\mathrm{Au}(100)$ with $23 \%$. The rest of terminations only account for $10 \%$ each one. This shape is similar, but not the same, as the truncated octahedron found in previous reports. ${ }^{55,81,82}$ Such a deviation is attributed to the van der Waals approach employed, which is known to impact surface properties. ${ }^{83}$ Surfaces energies computed via Grimme D2 $2^{72}$ with modified parameters for the metal ${ }^{73}$ did provide the expected truncatedoctahedral shape (Figure S1).

At low coverage, the effect of the organic ligand is quite significant. The previously dominant $\mathrm{Au}(111)$ and $\mathrm{Au}(100)$ surfaces drop to $12 \%$ and $15 \%$, respectively. In turn, the contribution from both chiral surfaces increases up to $68 \%$. Interestingly, while the chiral facets were equivalent in the clean particle ( $10 \%$ each), the presence of $\mathrm{L}$-cysteine drives the enantiomeric differentiation favoring $\mathrm{Au}(321)$ (38\%) over $\mathrm{Au}(32 \overline{1})(30 \%)$. At high coverage, $\mathrm{Au}(111)$ goes further down to $5 \%$ while $\mathrm{Au}(100)$ remains at $15 \%$. The enantiomer $\mathrm{Au}(321)(30 \%)$ still predominates over $\mathrm{Au}(32 \overline{1})$ (23\%), but the overall contribution from both chiral surfaces decreases to 


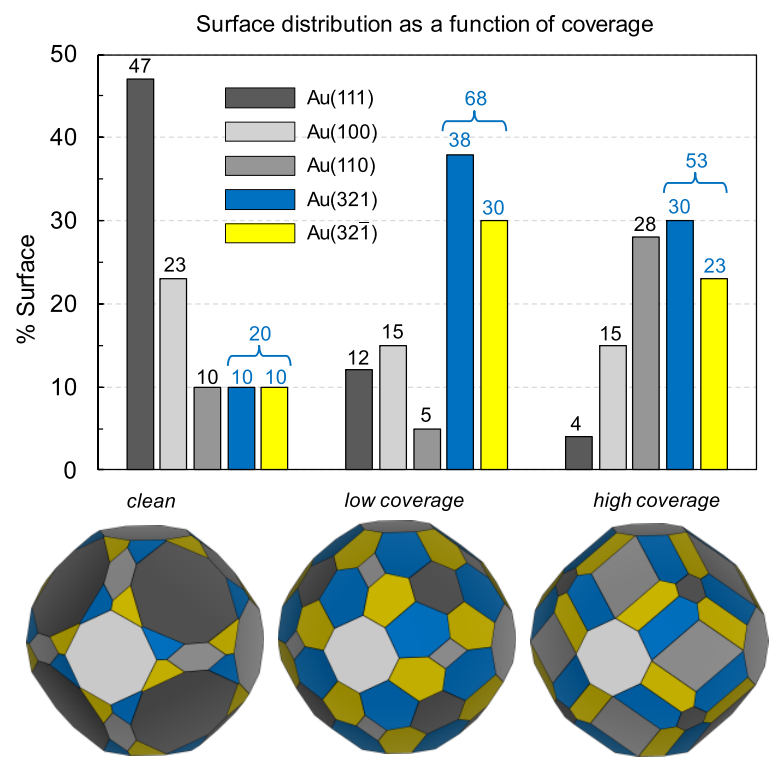

Figure 6. Wulff constructions of clean, low coverage, and high coverage of L-cysteine on AuNPs and surface distribution (\%).

$53 \%$ at the benefit of $\mathrm{Au}(110)$, which increases from $5 \%$ to $28 \%$. Therefore, although the relative enantiomeric discrimination is similar for both low- and high-coverage scenarios ( $8 \%$ and $7 \%$, respectively), the percentage of chiral surfaces is smaller for the latter one ( $68 \%$ and $53 \%$, respectively).

\section{CONCLUSIONS}

We present periodic DFT simulations combined with Wulff constructions to understand the enantiomeric enrichment driven by the amino acid L-cysteine on chiral gold surfaces. At low ligand coverage, the adsorption energy of L-cysteine on $\mathrm{Au}(321)$ is higher than that on $\mathrm{Au}(32 \overline{1})$, which promotes the enantiomeric discrimination of terminations during thermodynamic nanoparticle growth. At high ligand coverage, the trend remains the same, but now the contribution from chiral surfaces becomes smaller due to stabilizing on the achiral facet $\mathrm{Au}(110)$. Overall, we reveal the origin of the chiral induction by surface modifiers and demonstrate how the use of computational techniques can be employed as predictive tools for chiral nanostructures.

\section{ASSOCIATED CONTENT}

\section{S Supporting Information}

Additional energies and structures (PDF)

\section{AUTHOR INFORMATION}

\section{Corresponding Author}

*E-mail: mortuno@iciq.es.

\section{ORCID}

Núria López: 0000-0001-9150-5941

Manuel A. Ortuño: 0000-0002-6175-3941

Notes

The authors declare no competing financial interest.

\section{ACKNOWLEDGMENTS}

J.M.V. thanks Fundació la Caixa for a Summer Fellowship. M.A.O. acknowledges Juan de la Cierva Incorporación (IJCI2016-29762) and Beatriu de Pinós (2017-BP-00039) fellowships for financial support. The authors acknowledge generous computer resources at Caesaraugusta and technical support provided by BIFI University of Zaragoza (RES-QCM-2018-30005).

\section{REFERENCES}

(1) Sun, Y.; Xia, Y. Shape-Controlled Synthesis of Gold and Silver Nanoparticles. Science 2002, 298, 2176-2179.

(2) Liao, H.-G.; Zherebetskyy, D.; Xin, H.; Czarnik, C.; Ercius, P.; Elmlund, H.; Pan, M.; Wang, L.-W.; Zheng, H. Facet Development during Platinum Nanocube Growth. Science 2014, 345, 916-919.

(3) Xia, Y.; Xiong, Y.; Lim, B.; Skrabalak, S. E. Shape-Controlled Synthesis of Metal Nanocrystals: Simple Chemistry Meets Complex Physics? Angew. Chem., Int. Ed. 2009, 48, 60-103.

(4) Daniel, M.-C.; Astruc, D. Gold Nanoparticles: Assembly, Supramolecular Chemistry, Quantum-Size-Related Properties, and Applications Toward Biology, Catalysis, and Nanotechnology. Chem. Rev. 2004, 104, 293-346.

(5) Grzelczak, M.; Pérez-Juste, J.; Mulvaney, P.; Liz-Marzán, L. M. Shape Control in Gold Nanoparticle Synthesis. Chem. Soc. Rev. 2008, 37, 1783-1791.

(6) Lohse, S. E.; Murphy, C. J. The Quest for Shape Control: A History of Gold Nanorod Synthesis. Chem. Mater. 2013, 25, 12501261.

(7) Saha, K.; Agasti, S. S.; Kim, C.; Li, X.; Rotello, V. M. Gold Nanoparticles in Chemical and Biological Sensing. Chem. Rev. 2012, 112, 2739-2779.

(8) Dreaden, E. C.; Alkilany, A. M.; Huang, X.; Murphy, C. J.; ElSayed, M. A. The Golden Age: Gold Nanoparticles for Biomedicine. Chem. Soc. Rev. 2012, 41, 2740-2779.

(9) Yang, X.; Yang, M.; Pang, B.; Vara, M.; Xia, Y. Gold Nanomaterials at Work in Biomedicine. Chem. Rev. 2015, 115, 10410-10488.

(10) Stratakis, M.; García, H. Catalysis by Supported Gold Nanoparticles: Beyond Aerobic Oxidative Processes. Chem. Rev. 2012, 112, 4469-4506.

(11) Hutchings, G. J. Heterogeneous Gold Catalysis. ACS Cent. Sci. 2018, 4, 1095-1101.

(12) Kumar, J.; Eraña, H.; López-Martínez, E.; Claes, N.; Martín, V. F.; Solís, D. M.; Bals, S.; Cortajarena, A. L.; Castilla, J.; Liz-Marzán, L. M. Detection of Amyloid Fibrils in Parkinson's Disease Using Plasmonic Chirality. Proc. Natl. Acad. Sci. U. S. A. 2018, 115, 32253230.

(13) Myroshnychenko, V.; Rodríguez-Fernández, J.; PastorizaSantos, I.; Funston, A. M.; Novo, C.; Mulvaney, P.; Liz-Marzán, L. M.; García de Abajo, F. J. Modelling the Optical Response of Gold Nanoparticles. Chem. Soc. Rev. 2008, 37, 1792-1805.

(14) Gellman, A. J. Chiral Surfaces: Accomplishments and Challenges. ACS Nano 2010, 4, 5-10.

(15) Zaera, F. Chirality in Adsorption on Solid Surfaces. Chem. Soc. Rev. 2017, 46, 7374-7398.

(16) Ma, W.; Xu, L.; de Moura, A. F.; Wu, X.; Kuang, H.; Xu, C.; Kotov, N. A. Chiral Inorganic Nanostructures. Chem. Rev. 2017, 117, 8041-8093.

(17) Xiao, W.; Ernst, K.-H.; Palotas, K.; Zhang, Y.; Bruyer, E.; Peng, L.; Greber, T.; Hofer, W. A.; Scott, L. T.; Fasel, R. Microscopic Origin of Chiral Shape Induction in Achiral Crystals. Nat. Chem. 2016, 8, 326-330.

(18) Schaaff, T. G.; Knight, G.; Shafigullin, M. N.; Borkman, R. F.; Whetten, R. L. Isolation and Selected Properties of a $10.4 \mathrm{kDa}$ Gold: Glutathione Cluster Compound. J. Phys. Chem. B 1998, 102, 1064310646.

(19) Gautier, C.; Bürgi, T. Chiral Gold Nanoparticles. ChemPhysChem 2009, 10, 483-492. 
(20) Lee, H.-E.; Ahn, H.-Y.; Mun, J.; Lee, Y. Y.; Kim, M.; Cho, N. H.; Chang, K.; Kim, W. S.; Rho, J.; Nam, K. T. Amino-Acid- and Peptide-Directed Synthesis of Chiral Plasmonic Gold Nanoparticles. Nature 2018, 556, 360-365.

(21) Zheng, G.; Bao, Z.; Pérez-Juste, J.; Du, R.; Liu, W.; Dai, J.; Zhang, W.; Lee, L. Y. S.; Wong, K.-Y. Tuning the Morphology and Chiroptical Properties of Discrete Gold Nanorods with Amino Acids. Angew. Chem., Int. Ed. 2018, 57, 16452-16457.

(22) Zhou, Y.; Sun, H.; Xu, H.; Matysiak, S.; Ren, J.; Qu, X. Mesoporous Encapsulated Chiral Nanogold for Use in Enantioselective Reactions. Angew. Chem., Int. Ed. 2018, 57, 16791-16795.

(23) Bealing, C. R.; Baumgardner, W. J.; Choi, J. J.; Hanrath, T.; Hennig, R. G. Predicting Nanocrystal Shape through Consideration of Surface-Ligand Interactions. ACS Nano 2012, 6, 2118-2127.

(24) Boles, M. A.; Ling, D.; Hyeon, T.; Talapin, D. V. The Surface Science of Nanocrystals. Nat. Mater. 2016, 15, 141-153.

(25) Heinz, H.; Ramezani-Dakhel, H. Simulations of InorganicBioorganic Interfaces to Discover New Materials: Insights, Comparisons to Experiment, Challenges, and Opportunities. Chem. Soc. Rev. 2016, 45, 412-448.

(26) James, J. N.; Sholl, D. S. Theoretical Studies of Chiral Adsorption on Solid Surfaces. Curr. Opin. Colloid Interface Sci. 2008, 13, 60-64.

(27) Carchini, G.; Almora-Barrios, N.; Revilla-López, G.; Bellarosa, L.; García-Muelas, R.; García-Melchor, M.; Pogodin, S.; Błoński, P.; López, N. How Theoretical Simulations Can Address the Structure and Activity of Nanoparticles. Top. Catal. 2013, 56, 1262-1272.

(28) Tang, Q.; Jiang, D. Computational Insight into the Covalent Organic-Inorganic Interface. Chem. Mater. 2016, 28, 5976-5988.

(29) Hakkinen, H. The Gold-Sulfur Interface at the Nanoscale. Nat. Chem. 2012, 4, 443-455.

(30) Hong, G.; Heinz, H.; Naik, R. R.; Farmer, B. L.; Pachter, R. Toward Understanding Amino Acid Adsorption at Metallic Interfaces: A Density Functional Theory Study. ACS Appl. Mater. Interfaces 2009, 1, 388-392.

(31) Heinz, H.; Farmer, B. L.; Pandey, R. B.; Slocik, J. M.; Patnaik, S. S.; Pachter, R.; Naik, R. R. Nature of Molecular Interactions of Peptides with Gold, Palladium, and Pd-Au Bimetal Surfaces in Aqueous Solution. J. Am. Chem. Soc. 2009, 131, 9704-9714.

(32) Feng, J.; Pandey, R. B.; Berry, R. J.; Farmer, B. L.; Naik, R. R.; Heinz, H. Adsorption Mechanism of Single Amino Acid and Surfactant Molecules to $\mathrm{Au}\{111\}$ Surfaces in Aqueous Solution: Design Rules for Metal-Binding Molecules. Soft Matter 2011, 7, 2113-2120.

(33) Di Felice, R.; Corni, S. Simulation of Peptide-Surface Recognition. J. Phys. Chem. Lett. 2011, 2, 1510-1519.

(34) Wang, J.-G.; Selloni, A. First Principles Study of Fatty Acid Monolayers on $\mathrm{Au}(111)$. J. Phys. Chem. C 2009, 113, 8895-8900.

(35) Jha, K. C.; Liu, H.; Bockstaller, M. R.; Heinz, H. Facet Recognition and Molecular Ordering of Ionic Liquids on Metal Surfaces. J. Phys. Chem. C 2013, 117, 25969-25981.

(36) Gómez-Graña, S.; Goris, B.; Altantzis, T.; Fernández-López, C.; Carbó-Argibay, E.; Guerrero-Martínez, A.; Almora-Barrios, N.; López, N.; Pastoriza-Santos, I.; Pérez-Juste, J.; et al. Au@Ag Nanoparticles: Halides Stabilize $\{100\}$ Facets. J. Phys. Chem. Lett. 2013, 4, 22092216.

(37) Tang, Q.; Jiang, D. Comprehensive View of the Ligand-Gold Interface from First Principles. Chem. Mater. 2017, 29, 6908-6915.

(38) Bürgi, T. Properties of the Gold-Sulphur Interface: From SelfAssembled Monolayers to Clusters. Nanoscale 2015, 7, 15553-15567.

(39) Di Felice, R.; Selloni, A.; Molinari, E. DFT Study of Cysteine Adsorption on $\mathrm{Au}(111)$. J. Phys. Chem. B 2003, 107, 1151-1156.

(40) Di Felice, R.; Selloni, A. Adsorption Modes of Cysteine on $\mathrm{Au}(111)$ : Thiolate, Amino-Thiolate, Disulfide. J. Chem. Phys. 2004, 120, 4906-4914.

(41) Kühnle, A.; Molina, L. M.; Linderoth, T. R.; Hammer, B.; Besenbacher, F. Growth of Unidirectional Molecular Rows of Cysteine on $\mathrm{Au}(110)-(1 \times 2)$ Driven by Adsorbate-Induced Surface Rearrangements. Phys. Rev. Lett. 2004, 93, 086101.
(42) Höffling, B.; Ortmann, F.; Hannewald, K.; Bechstedt, F. Single Cysteine Adsorption on $\mathrm{Au}(110)$ : A First-Principles Study. Phys. Rev. B: Condens. Matter Mater. Phys. 2010, 81, 045407.

(43) Mateo-Martí, E.; Rogero, C.; Gonzalez, C.; Sobrado, J. M.; de Andrés, P. L.; Martin-Gago, J. A. Interplay between Fast Diffusion and Molecular Interaction in the Formation of Self-Assembled Nanostructures of S-Cysteine on $\mathrm{Au}(111)$. Langmuir 2010, 26, 4113-4118.

(44) Buimaga-Iarinca, L.; Morari, C. Effect of Conformational Symmetry upon the Formation of Cysteine Clusters on the $\mathrm{Au}(110)$ $(1 \times 1)$ Surface: A First-Principles Study. J. Phys. Chem. C 2013, 117, 20351-20360

(45) Popa, T.; Ting, E. C. M.; Paci, I. Chiral Effects in Amino acid Adsorption on $\mathrm{Au}(111)$ : A Comparison of Cysteine, Homocysteine and Methionine. Surf. Sci. 2014, 629, 20-27.

(46) Popa, T.; Paci, I. Structure and Chirality in Sulfur-Containing Amino Acids Adsorbed on $\mathrm{Au}(111)$ Surfaces. J. Phys. Chem. C 2015, 119, 9829-9838.

(47) Monti, S.; Carravetta, V.; Ågren, H. Simulation of Gold Functionalization with Cysteine by Reactive Molecular Dynamics. J. Phys. Chem. Lett. 2016, 7, 272-276.

(48) Kühnle, A.; Linderoth, T. R.; Hammer, B.; Besenbacher, F. Chiral Recognition in Dimerization of Adsorbed Cysteine Observed by Scanning Tunnelling Microscopy. Nature 2002, 415, 891-893.

(49) Fajín, A. J. L. C.; Gomes, J. R. B.; Cordeiro, M. N. D. S. DFT Study of the Adsorption of D-(L-)Cysteine on Flat and Chiral Stepped Gold Surfaces. Langmuir 2013, 29, 8856-8864.

(50) Sljivančanin, Z.; Gothelf, K. V.; Hammer, B. Density Functional Theory Study of Enantiospecific Adsorption at Chiral Surfaces. J. Am. Chem. Soc. 2002, 124, 14789-14794.

(51) Schillinger, R.; Šljivančanin, Ž.; Hammer, B.; Greber, T. Probing Enantioselectivity with X-Ray Photoelectron Spectroscopy and Density Functional Theory. Phys. Rev. Lett. 2007, 98, 136102.

(52) Wulff, G. Z. Zur Frage der Geschwindigkeit des Wachsthums und der Auflösung der Krystallflächen. Z. Kristallogr. - Cryst. Mater. 1901, 34, 449-530.

(53) Barmparis, G. D.; Lodziana, Z.; Lopez, N.; Remediakis, I. N. Nanoparticle Shapes by Using Wulff Constructions and FirstPrinciples Calculations. Beilstein J. Nanotechnol. 2015, 6, 361-368.

(54) Barmparis, G. D.; Honkala, K.; Remediakis, I. N. Thiolate Adsorption on $\mathrm{Au}(h k l)$ and Equilibrium Shape of Large ThiolateCovered Gold Nanoparticles. J. Chem. Phys. 2013, 138, 064702.

(55) Taylor, M. G.; Austin, N.; Gounaris, C. E.; Mpourmpakis, G. Catalyst Design Based on Morphology- and Environment-Dependent Adsorption on Metal Nanoparticles. ACS Catal. 2015, 5, 6296-6301.

(56) Kresse, G.; Furthmuller, J. Efficient Iterative Schemes for Ab Initio Total-Energy Calculations Using a Plane-Wave Basis Set. Phys. Rev. B: Condens. Matter Mater. Phys. 1996, 54, 11169-11186.

(57) Kresse, G.; Furthmüller, J. Efficiency of Ab-Initio Total Energy Calculations for Metals and Semiconductors Using a Plane-Wave Basis Set. Comput. Mater. Sci. 1996, 6, 15-50.

(58) Perdew, J. P.; Burke, K.; Ernzerhof, M. Generalized Gradient Approximation Made Simple. Phys. Rev. Lett. 1996, 77, 3865-3868.

(59) Rosa, M.; Corni, S.; Di Felice, R. Van der Waals Effects at Molecule-Metal Interfaces. Phys. Rev. B: Condens. Matter Mater. Phys. 2014, 90, 125448.

(60) Grimme, S.; Antony, J.; Ehrlich, S.; Krieg, H. A Consistent and Accurate Ab Initio Parametrization of Density Functional Dispersion Correction (DFT-D) for the 94 Elements H-Pu. J. Chem. Phys. 2010, 132, 154104.

(61) Kresse, G.; Joubert, D. From Ultrasoft Pseudopotentials to the Projector Augmented-Wave Method. Phys. Rev. B: Condens. Matter Mater. Phys. 1999, 59, 1758-1775.

(62) Li, Q.; Rellán-Piñeiro, M.; Almora-Barrios, N.; Garcia-Ratés, M.; Remediakis, I. N.; López, N. Shape Control in Concave Metal Nanoparticles by Etching. Nanoscale 2017, 9, 13089-13094.

(63) Makov, G.; Payne, M. C. Periodic Boundary Conditions in Ab Initio Calculations. Phys. Rev. B: Condens. Matter Mater. Phys. 1995, 51, 4014-4022. 
(64) Monkhorst, H. J.; Pack, J. D. Special Points for Brillouin-zone Integrations. Phys. Rev. B 1976, 13, 5188-5192.

(65) Momma, K.; Izumi, F. VESTA 3 for Three-Dimensional Visualization of Crystal, Volumetric and Morphology Data. J. Appl. Crystallogr. 2011, 44, 1272-1276.

(66) Alvarez-Moreno, M.; De Graaf, C.; López, N.; Maseras, F.; Poblet, J. M.; Bo, C. Managing the Computational Chemistry Big Data Problem: the ioChem-BD Platform. J. Chem. Inf. Model. 2015, 55, 95-103.

(67) Morales-Vidal, J. Database. DOI: 10.19061/iochem-bd-1-114.

(68) Bo, C.; Maseras, F.; López, N. The Role of Computational Results Databases in Accelerating the Discovery of Catalysts. Nat. Catal. 2018, 1, 809-810.

(69) McFadden, C. F.; Cremer, P. S.; Gellman, A. J. Adsorption of Chiral Alcohols on "Chiral" Metal Surfaces. Langmuir 1996, 12, 2483-2487.

(70) Singh-Miller, N. E.; Marzari, N. Surface Energies, Work Functions, and Surface Relaxations of Low-Index Metallic Surfaces from First Principles. Phys. Rev. B: Condens. Matter Mater. Phys. 2009, $80,235407$.

(71) Domingo, M.; Shahrokhi, M.; Remediakis, I. N.; López, N. Shape Control in Gold Nanoparticles by N-Containing Ligands: Insights from Density Functional Theory and Wulff Constructions. Top. Catal. 2018, 61, 412-418.

(72) Grimme, S. Semiempirical GGA-type Density Functional Constructed with a Long-Range Dispersion Correction. J. Comput. Chem. 2006, 27, 1787-1799.

(73) Almora-Barrios, N.; Carchini, G.; Błoński, P.; López, N. Costless Derivation of Dispersion Coefficients for Metal Surfaces. J. Chem. Theory Comput. 2014, 10, 5002-5009.

(74) Wilke, J. J.; Lind, M. C.; Schaefer, H. F., III; Császár, A. G.; Allen, W. D. Conformers of Gaseous Cysteine. J. Chem. Theory Comput. 2009, 5, 1511-1523.

(75) Kolesov, B. A.; Minkov, V. S.; Boldyreva, E. V.; Drebushchak, T. N. Phase Transitions in the Crystals of 1 - and dl-Cysteine on Cooling: Intermolecular Hydrogen Bonds Distortions and the SideChain Motions of Thiol-Groups. 1. L-Cysteine. J. Phys. Chem. B 2008, 112, 12827-12839.

(76) Almora-Barrios, N.; Novell-Leruth, G.; Whiting, P.; LizMarzan, L. M.; López, N. Theoretical Description of the Role of Halides, Silver, and Surfactants on the Structure of Gold Nanorods. Nano Lett. 2014, 14, 871-875.

(77) Since we compute $E_{\text {ads }}$ taking the solid-state energy of Lcysteine as reference, the vibrational entropic contributions of adsorbed molecules on gold surfaces will be canceled by those of the organic solid.

(78) Senftle, T. P.; Hong, S.; Islam, M. M.; Kylasa, S. B.; Zheng, Y.; Shin, Y. K.; Junkermeier, C.; Engel-Herbert, R.; Janik, M. J.; Aktulga, H. A.; et al. The ReaxFF Reactive Force-Field: Development, Applications and Future Directions. npj Comput. Mater. 2016, 2, 15011.

(79) Geada, I. L.; Ramezani-Dakhel, H.; Jamil, T.; Sulpizi, M.; Heinz, H. Insight into Induced Charges at Metal Surfaces and Biointerfaces using a Polarizable Lennard-Jones Potential. Nat. Commun. 2018, 9, 716.

(80) Tyson, W. R.; Miller, W. A. Surface Free Energies of Solid Metals Estimation from Liquid Surface Tension Measurements. Surf. Sci. 1977, 62, 267-276.

(81) Sivaramakrishnan, S.; Wen, J.; Scarpelli, M. E.; Pierce, B. J.; Zuo, J. Equilibrium Shapes and Triple Line Energy of Epitaxial Gold Nanocrystals Supported on $\mathrm{TiO}_{2}(110)$. Phys. Rev. B: Condens. Matter Mater. Phys. 2010, 82, 195421.

(82) Barmparis, G. D.; Remediakis, I. N. Dependence on CO Adsorption of the Shapes of Multifaceted Gold Nanoparticles: A Density Functional Theory. Phys. Rev. B: Condens. Matter Mater. Phys. 2012, 86, 085457.

(83) Patra, A.; Bates, J. E.; Sun, J.; Perdew, J. P. Properties of Real Metallic Surfaces: Effects of Density Functional Semilocality and van der Waals Nonlocality. Proc. Natl. Acad. Sci. U. S. A. 2017, 114, E9188-9196. 